\title{
The number of Mycobacterium leprae in the pretreatment biopsy-specimen does not determine the rate of response of patients with lepromatous leprosy to chemotherapy with acedapsone
}

\author{
L LEVY* \& C C SHEPARD † \\ * Department of Comparative Medicine, Hebrew University-Hadas- \\ sah Medical School, Jerusalem, Israel; †Center for Infectious \\ Diseases, Centers for Disease Control, Atlanta, Georgia, USA
}

Accepted for publication 24 September 1985

\begin{abstract}
Summary In a n attempt to explain wide patient-to-patient variation of the rate at which patients respond to chemotherapy with acedapsone, the relationship between the logarithm $\mathrm{m}_{10}$ of the number of Mycobacterium leprae in the patient's pretreatment skin-biopsy specimen, and the rapidity with which the organisms became non-infective for mice, was examined for a number of patients with previously untreated lepromatous leprosy, treated in the course of a clinical trial in Cebu, Philippines. Analysis of the data failed to reveal such a relationship.
\end{abstract}

\section{Introduction}

Acedapsone [4,4'-diacetamidodiphenylsulphone (DADDS)], which produces a prolonged, low plasma level of dapsone af ter intramuscular administration, ${ }^{1}$ has been shown to be an effective chemotherapeutic agent in clinical trials among patients with lepromatous leprosy. ${ }^{2,3}$ In the course of these trials, some patients responded as rapidly as patients treated with dapsone in full dosage, as measured by inoculation of mice with organisms recovered from skin-biopsy specimens obtained at intervals during treatment, whereas others responded much more slowly. Work was subsequently undertaken to identify the factors that determine the rate of response to treatment with acedapsone. To date, studies have shown that neither the susceptibility of the individual patient-strains of Mycobacterium leprae, all susceptible to dapsone administered to mice in a concentration of $0 \cdot 0001 \mathrm{~g} / 100 \mathrm{~g}$ diet or less, ${ }^{4}$ nor the ratio of monoacetyldapsone to dapsone in the plasma of the patient ${ }^{5}$ determines the rate at which the patients respond to

$\ddagger$ Deceased. 
treatment with acedapsone as monotherapy. Because analysis of the results of an earlier controlled clinical trial of clofazimine in several dosages ${ }^{6,7}$ had suggested that the rate at which patients responded to chemotherapy was determined in part by the logarithm 10 of the total number of $M$. leprae (LAFB) recovered from the patient's pretreatment skin biopsy specimen, we wondered if the same phenomenon could explain the observed differences of the rate of response to therapy with acedapsone.

\section{Materials and methods}

In a controlled clinical trial (the 'Rifampin II' trial), conducted among patients with previously untreated lepromatous and near-lepromatous leprosy at the Leonard Wood Memorial Leprosy Research Laboratory, Eversley Childs Sanitarium, Cebu, Philippines [Collaborative effort of the US Leprosy Panel (US-Japan Cooperative Medical Science Program) and the Leonard Wood Memorial, manuscript in preparation], 27 patients were randomly assigned to treatment by acedapsone, administered intramuscularly in a dosage of $225 \mathrm{mg}$ every 11 weeks. The same skin lesion was biopsied before, and at intervals of 4,12 and 24 weeks after the start of treatment. M. leprae were recovered from the skinbiopsy specimens, enumerated, and inoculated into the hind foot-pads of mice, single mice were sacrificed monthly for histopathologic examination of the inoculated foot-pads, and harvests of $M$. leprae were performed from pools, usually of 4 foot-pads, all as previously described.$^{8,}{ }^{9}$ The values for LAFB were calculated from the number of organisms recovered from the pretreatment skinbiopsy specimens, all of which had been obtained with a biopsy-punch, and which varied in weight from 50 to $100 \mathrm{mg}$. SCORE, a measure of the rate of response to therapy, was calculated as described earlier; ${ }^{7}$ values of 1,2 or 3 were assigned to negative, weakly positive, and positive mouse inoculations, respectively, and SCORE was defined as the sum of the results of the inoculations performed after 4, 12 and 24 weeks of treatment. The smaller the value for SCORE, the more rapid the response to chemotherapy, as measured by inoculation of mice. The relationship between LAFB and SCORE was analysed by means of the Kendall rank correlation coefficient, tau $^{10}$

\section{Results}

The results of this study of 27 patients are presented in Table 1, in which the values of LAFB and SCORE are presented for each patient, the patients arranged in descending order of their LAFB values. These results show that there was considerable patient-to-patient variation of SCORE. However, the values for LAFB of the patients' pretreatment skin-biopsy specimens do not appear to be correlated with the values for SCORE. 
Table 1. SCORE as a function of LAFB among lepromatous patients treated with acedapsone as monotherapy in the Rifampin II trial

\begin{tabular}{lcclcc} 
Patient & LAFB* & SCORE & Patient & LAFB* & SCORE \\
\hline MAHU & $7 \cdot 98$ & 7 & COND & $7 \cdot 48$ & 5 \\
DIWA & $7 \cdot 97$ & 5 & MAGL & $7 \cdot 43$ & 3 \\
PEND & $7 \cdot 91$ & 3 & DOMI & $7 \cdot 42$ & 7 \\
ALIM & $7 \cdot 88$ & 7 & SUMO & $7 \cdot 42$ & 3 \\
PAGA & $7 \cdot 85$ & 7 & SALA & $7 \cdot 39$ & 5 \\
ORTE & $7 \cdot 84$ & 6 & BAGU & $7 \cdot 32$ & 7 \\
MARC & $7 \cdot 76$ & 4 & GARN & $7 \cdot 23$ & 9 \\
ORDO & $7 \cdot 75$ & 7 & PENA & $7 \cdot 23$ & 5 \\
DICD & $7 \cdot 71$ & 3 & FLOR & $7 \cdot 12$ & 5 \\
BACU & $7 \cdot 64$ & 7 & PATD & $7 \cdot 03$ & 9 \\
RICA & $7 \cdot 61$ & 5 & ILLU & $6 \cdot 76$ & 9 \\
ELLE & $7 \cdot 58$ & 3 & SUAR & $6 \cdot 52$ & 6 \\
LAPI & $7 \cdot 53$ & 7 & ALIN & 6.36 & 6 \\
MERC & $7 \cdot 50$ & 9 & & & \\
\hline
\end{tabular}

* LAFB $v s$. SCORE: $t a u=-0 \cdot 142 ; P=0 \cdot 335$.

\section{Discussion}

The rate at which patients with lepromatous leprosy respond to chemotherapy is usually measured by inoculation of mice in the hind foot-pad with a standard number of $M$. leprae recovered from serial skin biopsy specimens; organisms recovered from untreated patients almost always multiply in the mice, whereas the decreasing proportion of viable organisms recovered from patients during effective treatment is detected, after a shorter or longer period of treatment, as failure of bacterial multiplication. The duration of therapy before the patient's $M$. leprae become unable to multiply in mice has been shown to vary from regimen to regimen. ${ }^{11}$

In the analysis of the results of a trial of intermittently administered clofazimine,${ }^{6}$ it was noted that patients whose pretreatment biopsy-specimens contained smaller numbers of organisms responded more rapidly than did those whose specimens contained larger numbers. ${ }^{7}$ It was suggested that the difference in the rates at which patients responded to clofazimine had resulted from an artefact. Because a standard number of $M$. leprae is inoculated into mice, those bacterial suspensions containing larger numbers of organisms undergo greater dilution than do those containing fewer organisms; the human tissue components included in the suspensions are diluted to the same degree as the organisms. Thus, it appeared likely that the contaminating human tissue components, present in 
the less diluted bacterial suspensions (those yielding a smaller value for LAFB) in greater concentration, inhibited multiplication of $M$. leprae in mice, thus giving the appearance of a more rapid response to treatment.

Although this hypothesis had not been tested, some corroborating evidence was found. In the course of the first demonstration of 'persisting' M. leprae in patients treated with dapsone for at least 10 years, ${ }^{12}$ organisms from the same suspensions multiplied more frequently in thymectomized-irradiated than in normal mice, although the inocula were small, and in many cases no organisms could be counted. Because of the small numbers of organisms available from the biopsy-specimens, dilution of the bacterial suspensions had been minimized. It appeared likely that the poorer growth of $M$. leprae in normal mice reflected the greater ability of the normal mouse to respond immunologically to the foreign tissue components inoculated together with the organisms.

Additional evidence for such a phenomenon was the demonstration, in the course of a study of the effect of mouse interferon injected locally into the $M$. leprae-infected foot-pad, ${ }^{13}$ that multiplication of the organisms was inhibited by both the 'interferon control' (a filtrate of an L-cell culture that had not been infected with Newcastle disease virus, and had not produced interferon) and foetal calf serum, a component of the cell-culture medium. Finally, in the course of a study of the survival of $M$. leprae after freezing in various media (L Levy, unpublished data), organisms that had been suspended in either 90 or $100 \%$ rabbit serum but had not been frozen were inhibited from multiplying in the mouse foot-pad.

It is clear, however, that the outcome of this analysis of the results of a clinical trial of monotherapy with acedapsone, is not consistent with the hypothesis that contamination with human tissue is one of the factors that determine the rate at which lepromatous patients respond to chemotherapy, as measured by inoculation of mice. Thus, another explanation must be sought for the patient-to-patient variation of the rate of response to acedapsone. That 17 of the 27 patients, the results of whose study are presented here, were those shown earlier ${ }^{4}$ to harbour $M$. leprae susceptible to dapsone administered in a concentration no larger (and frequently smaller) than $0.0001 \mathrm{~g} / 100 \mathrm{~g}$ mouse diet, and that, some years after these patients had been recruited, primary resistance to dapsone was demonstrated to be rare in the population from which these patients had been drawn, ${ }^{14}$ should exclude primary resistance to dapsone as a factor determining the rate of response to acedapsone in this study.

\section{Acknowledgments}

The authors acknowledge with thanks the assistance of Mr Brian Plikaytis, Centers for Disease Control, who performed the statistical analysis. The authors also wish to record their pleasure in the renewal of a long standing collaboration 
with the Leonard Wood Memorial, who made available the data analysed in this paper.

\section{References}

${ }^{1}$ Glazko AJ, Dill WA, Montalbo RG, Holmes EL. A new analytical procedure for dapsone. Am J Trop Med Hyg, 1968; 17: 465-73.

2 Shepard CC, Tolentino JG, McRae DH. The therapeutic effect of 4,4'-diacetyldiaminodiphenylsulfone (DADDS) in leprosy. Am J Trop Med Hyg, 1968; 17: 192-201.

${ }^{3}$ Shepard CC, Levy L, Fasal P. The death rate of Mycobacterium leprae during treatment of lepromatous leprosy with acedapsone (DADDS). Am J Trop Med Hyg, 1972; 21: 446-9.

${ }^{4}$ Levy L, Peters JH. Susceptibility of Mycobacterium leprae to dapsone as a determinant of patient response to acedapsone. Antimicrob Ag Chemother, 1976; 9: 102-12.

${ }^{5}$ Peters JH, Murray JF Jr, Gordon GR, Levy L, Russell DA, Scott GC, Vincin DR, Shepard CC. Acedapsone treatment of leprosy patients: response versus drug disposition. Am J Trop Med Hyg, 1977; 26: 127-36.

${ }^{6}$ Collaborative effort of the U.S. Leprosy Panel (U.S.-Japan Cooperative Medical Science Program) and the Leonard Wood Memorial. Spaced clofazimine therapy of lepromatous leprosy. Am J Trop Med Hyg, 1976; 25: 437-44.

7 Collaborative effort of the U.S. Leprosy Panel (U.S.-Japan Cooperative Medical Science Program) and the Leonard Wood Memorial. A statistical analysis of two chemotherapy trials in lepromatous leprosy. I. The response to therapy as measured by inoculation of mice. $\mathrm{Am} \mathrm{J}$ Trop Med Hyg, 1978; 27: 1005-14.

${ }^{8}$ Shepard CC. The experimental disease that follows the injection of human leprosy bacilli into footpads of mice. $J$ exp Med, 1960; 112: 445-54.

${ }^{9}$ Shepard CC, McRae DH. A method for counting acid-fast bacteria. Int J Lepr, 1968; 36:78-82.

${ }^{10}$ Siegel S. Non-parametric statistics for the behavioral sciences. McGraw-Hill, New York, 1956; 213-23.

11 Shepard CC. A brief review of experiences with short-term clinical trials monitored by mousefoot-pad inoculation. Lepr Rev, 1981; 52: 299-308.

12 Waters MFR, Rees RJW, McDougall AC, Weddell AGM. Ten years of dapsone in lepromatous leprosy: Clinical, bacteriological and histological assessment and the finding of viable leprosy bacilli. Lepr Rev, 1974; 45: 288-98.

${ }^{13}$ Levy L, Merigan TC. Inhibition of multiplication of Mycobacterium leprae by polyinosinicpolycytidylic acid. Antimicrob Ag Chemother, 1977; 11: 122-5.

${ }^{14}$ Guinto RS, Cellona RV, Fajardo TT, de la Cruz EC. Primary dapsone resistant leprosy in Cebu, Philippines. Int J Lepr, 1981; 49: 427-30. 